\title{
Preface for Marcel Waldinger special issue on premature ejaculation
}

\author{
Ege Can Serefoglu ${ }^{1,2} \cdot$ Berend Olivier $^{3,4,5} \cdot$ Paddy K. C. Janssen ${ }^{6,7}$. \\ Stephen De Pretre ${ }^{8,9} \cdot$ Eelke Snoeren $^{10}$
}

Received: 29 August 2019 / Revised: 29 August 2019 / Accepted: 29 August 2019 / Published online: 13 September 2019

(c) The Author(s), under exclusive licence to Springer Nature Limited 2019

\section{A Capricorn is gone}

During a break in one of the hectic sexual medicine congresses, I was telling him the problems I was encountering in my academic career, yet again. With an abrupt interruption, he asked me my zodiac sign. I was perplexed by this question and after a moment of silence, I said "you are one of the greatest neuroscientists, do not tell me that you believe in that crap". He gave a warm and wise smile, a smile that we have rarely seen on him. He said, "there are things even I could not explain scientifically, it does not mean that they do not exist. I

Ege Can Serefoglu

egecanserefoglu@hotmail.com

1 Department of Urology, Bahceci Health Group, Istanbul, Turkey

2 Department of Embryology \& Histology, Medipol University, Istanbul, Turkey

3 Neurobiology, Groningen Institute for Evolutionary Life Sciences, University of Groningen, Groningen, The Netherlands

4 Department of Psychopharmacology, Utrecht Institute for Pharmaceutical Sciences, Science Faculty, Utrecht University, Utrecht, Netherlands

5 Department of Psychiatry, Yale University School of Medicine, New Haven, CT, USA

6 Department of Central Hospital Pharmacy, Viecuri Hospital Venlo, Venlo, The Netherlands

7 Department of Clinical Pharmacy and Toxicology, Maastricht University Medical Center, Maastricht, The Netherlands

8 Sapphire Pharmaceuticals International Ltd., Hong Kong, SAR, China

9 Atlas Pharmaceuticals bvba, Brugge, Belgium

10 Department of Psychology, UiT The Arctic University of Norway, Troms $\emptyset$, Norway cannot prove any scientific evidence but the astrology theory perfectly explains many aspects in my life."

Probably because of the blank expression on my face, he retorted, "You sound like a Capricorn, I am a Capricorn too". He continued by saying "my perseverance, my patience and my diligence perfectly match with the personality traits of a Capricorn. I was like that since my childhood. I always had issues conforming with the crowd. I always enjoyed observing crowds from a distance. During my school days, my peers found my behavior odd and as a result, I was always bullied by them. I never cared about that. I persevered with the things I cared for and enjoyed doing... knowing at the end I would attain my goals successfully. Quite often, I may react to them explosively at the very end. You can also see these reactions in my papers too. I always had to work hard with a strong sense of focus and determination because I always had something to prove to the world and to myself".

For many, Dr Waldinger was a grumpy professor who expressed his controversial thoughts in a direct and sharp manner. But for a handful of us, he was a great mentor and a true friend. Being a real scientist, he never cared about being "politically correct". In his perspective, there was either right or wrong and, there was nothing in between. We will and shall miss him greatly.

After my appointment as the EIC of IJIR: Your Sexual Medicine Journal, Dr Waldinger was one of the first to personally congratulate me. He was genuinely supportive and encouraging in my decision to accept this position. Recently, he submitted his latest works to our Journal and we wanted to publish them in a special "Premature Ejaculation" issue to honor his legacy. Below, you will also find the words of his real friends, co-workers and students. We will always remember him and shall walk on the path he has paved for us.

Ege Can Serefoglu 


\section{Marcel Waldinger: scientist and friend}

I met Marcel Waldinger halfway through the nineties during a neuroscience meeting in the Netherlands, where I gave a talk about pharmacology and sexual behavior in the male rat. Afterwards, Marcel approached me and told about his human studies on the effects of SSRIs on premature ejaculation (PE). At that time Solvay Duphar, a Dutch pharmaceutical company that had introduced the SSRI fluvoxamine as antidepressant into the market, employed me. It soon became clear during these first treatment years that all SSRIs have sexual inhibitory side effects. Marcel, a clever scientist, was able to use these 'side effects' of SSRIs in depression and turned them into 'therapeutic effects' in PE. He was the first to perform placebo-controlled studies in PE using different SSRIs and applied the 'stopwatch' technology to standardize the PE studies. In these studies the various SSRIs appeared not equally effective in inhibiting PE and fluvoxamine appeared the least effective. This was actually, the start of our lifelong collaboration because we decided to start studies of SSRIs on sexual behavior in the male rats in order to investigate potential differences in mechanisms behind the differential activity of SSRIs in inhibiting ejaculation in human and rat males. This research cumulated in Marcel's PhD-thesis, titled 'When seconds count: selective serotonin reuptake inhibitors and ejaculation', that he defended at Utrecht University on November 14, 1997 under supervision of Prof Michiel Hengeveld and myself. Intriguingly, Marcel was next to an astute clinical researcher, also an excellent neuroscientist, with a broad interest in and knowledge of fundamental processes in the brain. Since his PhD-time we have collaborated intensively on several aspects of male (and female) sexual behavior and dysfunctions. Marcel was a translational scientist, and heavily involved, along with his continuing human work, in our animal research. We extensively collaborated on research of animal (rat) models of sexual behavior predictive for human sexual (dys) functions, like PE or delayed ejaculation. Marcel was appointed professor of sexual pharmacology at Utrecht University in 2009, and contributed as supervisor to four $\mathrm{PhD}$-theses, covering genetic research in human $\mathrm{PE}$ (Paddy Janssen), pharmacological treatment of sexual dysfunction in human females (Jos Bloemers), male rat models of sexual dysfunction (Johnny Chan) and female rat models of sexual behavior and dysfunctions (Eelke Snoeren). Marcel has published extensively over the last decades and contributed to both human clinical and preclinical research, truly a translational scientist. In a recent search in Web of Science, Marcel had published 126 times, was cited more than 5000 times and had an $\mathrm{H}$-index of 40, showing that his research is acknowledged and of great quality. Recently, we were discussing new research possibilities in the field of ondemand treatment of PE and delayed or anejaculation.
Unfortunately, we have to continue our research without the stimulating clinical input from Marcel. I will miss him enormously, not only as scientist, but particularly as a very good friend.

Berend Olivier

\section{I was fortunate to have been one of his PhD students}

As a professor Marcel supervised various $\mathrm{PhD}$ candidates. I was fortunate to have been one of these candidates. I have benefited from Marcel's broad knowledge and clinical experience, many informative conversations, and the informal atmosphere in which the details of the studies were discussed. The equivalency and sincerity that Marcel has always applied in our cooperation are an example for me. After the PhD trajectory, our cooperation in research continued unchanged and has developed further with currently a focus on genetics.

Paddy K. C. Janssen

\section{Marcel: an endless fountain of knowledge}

I remember the very first time I met Marcel in his practice in Antwerp. He interrogated me on every aspect of my knowledge of PE and I walked out sweaty and nervous, wondering how I did and if I would have a passing grade. It was a nerve wracking experience, giving me flashbacks to my student days, but it was the start of a treasured friendship, which took us to many countries and a few continents.

Marcel was an endless fountain of knowledge in many areas and aspects, not only in PE, but also in psychiatry, pharmacology, the human brain and anything Tin Tin related. Marcel had a great sense of humor, we could laugh at the same jokes and he was my source of silly cartoons, which made me laugh every time he sent them. After a busy day, close to midnight when the world was quiet, it was a breath of fresh air to talk with Marcel about anything that crossed our minds.

Marcel was a prolific writer and researcher and it is hard to find any article mentioning PE that does not quote any of Marcel's articles or research. Marcel's work and vision created the academic foundation of an entire industry, a feat very few academics can claim. And all of this whilst never compromising his academic credibility, or giving in to commercial pressure.

Marcel is dearly missed by his partner Trudy and all those of us who knew him and whose lives he touched. The world has lost a great scientist, and we all have lost a great friend.

Stephen De Pretre 


\section{The world has lost a very dear and brilliant man}

The world lost a very dear and brilliant man when Prof Dr Marcel Waldinger passed away this year. I am proud that I got to know him well, and had the chance to learn a lot from him as a scientist. He was passionate about his work related to men and womens sexual dysfunctions, with a special focus on PE, postorgasm illness syndrome, and persistent sexual arousal syndrome. Our relationship started with him as my $\mathrm{PhD}$ co-supervisor. Although he was a psychiatrist with a main research focus in clinical studies, he was always very supportive and interested in my work as neurobiologist working with rat models. He was an ambitious man who was always eager to learn more and expand the knowledge in the field of sexual dysfunctions. He understood the value of basic translational research for his field and always tried to spread his interest in the society. I got to know him even better after my PhD, when we kept in touch and he invited me on a regular basis to the ESSM/ISSM meetings. He was definitely an advocate for bringing basic neurobiology into these meeting for clinicians, and at the same time strongly encouraged me to keep track of the translational value of my own work. If I lost myself in the basic neuroscience, it was Marcel who always reminded me that there is more than a neuron. In addition, he was also a very pleasant man to talk to. He was always in for brainstorm sessions about crazy ideas, or just social chatting during a dinner. He has had a large influence on my development as a scientist and person, and I am very grateful for that. It is sad we have to miss him far too soon.

Eelke Snoeren

\section{Compliance with ethical standards}

Conflict of interest The authors declare that they have no conflict of interest.

Publisher's note Springer Nature remains neutral with regard to jurisdictional claims in published maps and institutional affiliations. 